\title{
The Magic and Mysteries of Teaching ESL
}

\author{
Dan Manolescu ${ }^{1}$ \\ ${ }^{I}$ Freelance ESL Instructor and Award-Winning Author, the United States
}

\begin{tabular}{|c|c|}
\hline Article Info & \\
\hline Article history: & Abstract \\
\hline Received: 28 May 2021 & The present review article aims to emphasize the importance of ESL \\
\hline Revised: 23 July 2021 & as a relevant tool, not only in education, but in global communication \\
\hline Accepted: 24 July 2021 & $\begin{array}{l}\text { as well. While different approaches to the teaching of ESL and its } \\
\text { methodological implications still pose challenges to teachers and }\end{array}$ \\
\hline $\begin{array}{l}\text { Keywords: } \\
\text { ESL, Motivating Learning, } \\
\text { Communication }\end{array}$ & $\begin{array}{l}\text { learners all over the world, educators should be made aware of the } \\
\text { colossal power of this new tool that plays such an important role in } \\
\text { teaching and learning about other cultures, in exchanging ideas and }\end{array}$ \\
\hline Paper Type & new concepts, and eventually in making the world a better place to \\
\hline Review Article & $\begin{array}{l}\text { live, learn, and grow. Four basic principles are introduced and } \\
\text { discussed in detail, with a focus on the idea that lessons should be }\end{array}$ \\
\hline Corresponding Author: & $\begin{array}{l}\text { interesting, informative, communicative, and motivating. ESL, with } \\
\text { its magic and mysteries, may very well be a formidable tool in }\end{array}$ \\
\hline Dan Manolescu & $\begin{array}{l}\text { learning not only about language, but also about the way we } \\
\text { communicate witheachother. }\end{array}$ \\
\hline $\begin{array}{l}\text { Email: } \\
\text { Danmanolescu@attnet }\end{array}$ & \\
\hline
\end{tabular}

\section{Introduction}

English as a Second Language (ESL) is a special breed. In the United States, it started in Dade County, Florida, in 1963 as a government-supported bilingual program, but it soon attracted the attention of educators who wanted to replicate and emulate the example set by the original program. In 1966, the first national organization was founded: TESOL Teachers of English to Speakers of Other Language - and in time it grew into an international professional organization.

ESL (English as a Second Language) does not have a long history but, in a relatively short period of time, it developed into a global phenomenon. We can easily say that it encompasses all walks of life, all cultures, all religions, all skin colors, all genders, and all continents. It has no geographic boundaries or time regulations. It's growing out of the need for communication and the love of the language.

\section{Discussion}

There is something special about teaching ESL and the teachers can detect it as soon as they walk into a classroom and meet their students. This kind of special is called MAGIC. It is difficult to describe, but you can feel it, you can sense it, and you can experience it alone or together. ESL is tinged with magic and rich in mysteries. The magic of the classroom activities 
and the style of each academic skill create an aura of magic with consequences behind the walls of the building and after the class hours. Schools and educators create curricula and syllabi to stream the huge volume of information and resources, but the ultimate goal is to teach each other and to learn from each other. Very few disciplines include the reciprocal rapport and the bridge between the classroom and the community. ESL does it 24/7 and it competes with industries and world economies with a speed that does not show any signs of stopping.

Linguists became well aware of the challenges presented by the newness of ESL, not only because it grew out of an existing discipline - and had to be defined accordingly - for teachers and students alike, but also because it required a radically new approach in methodology.

The present-day teacher of English is a far cry from the old-time schoolmaster who taught by parsing and diagramming sentences on the board and by reading to the class pieces of abstruse poetry that the class could not understand and appreciate. He (or she) is today a very practical-minded person, who is fully aware of the pitfalls of the language and the latest scientific and educational devices for circumventing them. He seldom tries to teach English in a vacuum, but relates the subject to all of life's manifold activities, as well as to the other subjects of the curriculum. Above all, he is no longer a stuffy grammarian of the prescriptive school, but a broadminded person who realizes that language is perpetually changing, and allowances must be made for this fact. (Pei, 1967)

Dealing with ESL students means dealing with students from various cultures. Teachers should be aware of the differences and nuances of the language character and make sure they approach their students with respect and understanding. The etiquette of communication can be easily acquired by accepting that each student is a separate entity and they all come from different backgrounds. Here are some generalities to keep in mind from Sundem, Krieger \& Pickiewicz (2008):

1. Many cultures see eye contact as aggressive or intimate (especially between the genders).

2. Spanish-speaking, Arabic-speaking, and Asian students may be comfortable with less personal space and more physical contact than students (and teachers) experienced with American culture. [...]

3. Korean families may place extreme importance on education and can become upset by the appearance of their child's underachievement.

4. Parents of Asian students relate to teachers more formally than do their American counterparts.

5. Spanish-speaking students might offer immediate respect for females in authority roles while withholding respect form female peers.

6. Arabic-speaking students may have difficulties with females making decisions and exercising authority. 
7. Nodding and saying "yes" in Asian cultures demonstrates hearing but not necessarily agreement.

8. Spanish-speaking students may prioritize family obligations over education.

9. Copying schoolwork may be acceptable to students from former Eastern-bloc countries.

10. Students from Asian countries might excel in memorization but have difficulties with reading comprehension.

In other words, ESL instructors should be able to walk the fine line between cultures. Before we look a little deeper into the unique characteristics and facets of ESL, let us admire this "marvelous invention" called language:

Of all mankind's manifold creations, language must take pride of place. Other inventions - the wheel, agriculture, sliced bread - may have transformed our material existence, but the advent of language is what made us human. Compared to language, all other inventions pale in significance, since everything we have ever achieved depends on language and originates from it. Without language, we could never have embarked on our ascent to unparalleled power over all other animals, and even over nature itself." (Deutscher, 2005)

What is the magic of ESL? What is so attractive and appealing is the wide scope of learning ESL and the vision of being able to speak, read, write like a native. And if, in some cases, students still keep a part of their own culture and vocabulary, so much the better. This is what each mystery reveals when approached properly, with respect and mutual understanding. Each new reading passage or listening exercise is a mystery in itself and nobody knows better than those involved in the teaching process day in and day out. The rewards are endless when teachers and students discover together the minutia of a lesson objective, or when after weeks, months or even years of learning, they go back and reflect. The accomplishments are great and words cannot express the gratitude of those who open the door and let English enter their life. It's not only the language; it entails basic beliefs, assumptions and values, body language, facial expressions - they are all ingrained in the native speakers and ESL students should be made aware of that.

There are no secrets, but there are lots of small details that come into action when we start looking at the whole ESL concept. Let's start with four basic principles that linguists in general and ESL educators, in particular, would recommend. Lessons should be interesting, informative, communicative, and motivating. A quick presentation of these major concepts are discussed in detail. 


\section{Interesting}

The first and most important unwritten rule, I think, is to find the teaching material that presents itself as attractive and very, very interesting. No matter if we delve into vocabulary, grammar, reading techniques, listening exercises, or writing assignments, students should be somehow attracted not only by the main focus but also by the inherent and interesting quality of what they face for the first time. The subject matter and the way we present the information in the classroom should lure the students into the classroom instruction. ESL students are learning English for various reasons, but when they sit in a classroom, they expect to learn new things and the visual aspect, the combination of several classroom activities, (in other words, everything) should entertain and provide food for thought.

\section{Informative}

Knowledge comes in many facets, and the impact of the new material in the classroom should delight but also inform the learner. The teacher is the guide who organizes and empowers the students to make the instruction process meaningful. On a daily basis, we acquire information about the weather, politics, travel, sports, business, family matters, or entertainment. By the same token, every day in school is a day students learn to perform a certain task, practice new vocabulary, listen to dialogues, mini speeches or conversations, and in doing so improve their skills. At the end of each class period, students should be able to say, "I learned something today. My classroom experience was worth my effort, and I left empowered with something new, more interesting and more informative than I expected." Our goal is to exceed the student's expectations - which seems quite challenging for any educator but makes teaching a rewarding experience. If the feedback we provide is clear and positive, students will build on what they already know. A college professor once said that, the human mind, once expanded by knowledge, can never go back to its original shape.

\section{Communicative}

With so much to learn, absorb, and process, students should be able to take their recently acquired knowledge and apply it right away, be it in a casual conversation, or in another class with a different or similar focus. The need to exchange information should be instilled in the learner's mind so they can find a useful application but also test the depth and width of the previously learned experience. Practice is the most obvious segue to the next step, which is always inter-human communication. "Good instruction teaches students to do something." This is the main idea behind Teaching for Competence by Howard Sullivan and Norman Higgins (1983). The act of teaching does not consist of simply presenting information; we teach our students to do something with that knowledge.

How do we go about communicating with our students? In some cases, this is an art, and it takes some time to communicate the learning objectives to the students, but at the same time find a motivator. The best way to achieve this would be to inform the students of the value of what they will be learning. We should "explain why the knowledge or skill is important in its 
own right and/or as a necessity for learning other knowledge or skills. It is helpful to relate the usefulness of the new learning to life outside the school, as well as the previous or future school work. Whenever possible, you should also emphasize the importance of the objective for students' immediate needs or interests, rather than for more remote, long-range matters." (Sullivan \& Higgins 1983)

In other words, your (teacher's) role is to "provide conditions that help all students learn as well as possible, rather than one in which you simply make information and resources available for students to learn according to their abilities. If you present the information for performing a task but do not provide appropriate practice, the top students may still perform quite well because of their better ability to interpret and apply the information. Less able students, however, are unlikely to be able to perform the task without an opportunity to practice it. Good instruction will include practice of the exact task stated in the objective because such practice helps students learn. (Sullivan \& Higgins 1983)

\section{Motivating}

When we decide what skills we teach, we have handbooks, manuals, textbooks, websites, our own experience as teachers, and sometimes the students' previous classroom experience. We also have curricula, and we can develop our objective sheets for each separate skill. What we do NOT have is the student's motivation. This is something we need to think about very seriously and find ways to make the ESL students aware that learning also involves their own motivation. A quick walk through Motivating Learning by Jill Hadfield and Zoltan Dornyei (2011) will give you a chance to see the multiple ways we can resort to when it comes to motivation. According to the authors, teachers must create a vision for ESL students. The goals are not good enough and instead they must be replaced by a clear vision. The example they give is that young people can set the goal of becoming a doctor, but the vision will make them aware of what they will feel during their first day in the professional life of doctors. Extrapolating this idea, we might say that the ESL students' goal is to learn English, but the vision would involve them in conversations with native speakers in society, at the airport, the bank, or the department store, and would make them feel comfortable in any culture using English as a Second Language.

The vision would give them a feeling of accomplishment. The skills they learn in the classroom would enable them to do certain things in English.

"Doing describes what a person does to express himself in action of some kind. [.. . ] Americans insist on identifying an agent who can take purposeful and sequential action. The concepts of motive and motivation provide the link between action on one hand and the agent (and his purposes) on the other hand. Motives are attributes of the individual which arouse him to action. The concept of motivation reveals the connection and direction in a sequence of 
actions and, in everyday life, provides a convenient explanation for performance. It is appropriate to say someone succeeds or excels because he is well motivated." (Stewart, 1997)

\section{Conclusion}

An exhaustive approach to the teaching of ESL will always become relevant if we delve deep into the many aspects of the methodology, the types of classroom or online activities, and the intrinsic value of the magic and the mysteries presented by the complexity of the whole process to everybody in the field of ESL. Let us also remember that language is a miracle itself, and one of its most important assets is the fact that language allows us to put sounds together "into an infinite variety of subtle senses." In other words, "The wheels of language run so smoothly that one rarely bothers to stop and think about the resourcefulness and expertise that must have gone into making it tick" (Deutscher 2005).

In a nutshell, with proper knowledge and awareness of the teaching challenges, ESL may very well be a formidable tool in learning not only about language and other cultures, but also about the way we communicate with each other. And maybe, just maybe, besides the goal and the journey, the company we keep when we engage in the process of teaching and learning might provide us with the unexpected thrill and challenge. And that is why information-seeking creatures (also known as teachers) will always look for the magic and the mysteries of ESL.

\section{Conflict of Interest}

The author of the article declare no conflict of interests.

\section{Funding}

None

\section{References}

Crystal, D. (2006). How Language Works. Woodstock \& New York: Overlook Press.

Deutscher, G. (2005) The Unfolding of Language. Henry Holt and Company, New York.

Hadfield, J. \& Dornyei, Z. (2011). Motivating Learning. London and New York: Routledge.

Jason, K. and Posner, H. (1995). Explorations in American Culture. Boston, Massachusetts: Heinle \& Heinle.

Littlewood, W. (1981). Communicative Language Teaching. Cambridge: Cambridge University Press.

Manolescu, D. (2019). TIPS, A Guidebookfor Teaching Excellence in ESL. Columbus, Ohio: Gatekeeper Press.

Pei, M. (1967). The Story of the English Language, J. B. Lippincott Company, Philadelphia and New York.

Stewart, E. C. (1997) American Assumptions and Values: Orientation to Action [in] Toward 
Internationalism. Second Edition. Boston: Heinle \& Heinle.

Sullivan, H. \& Higgins, N. (1983). Teaching for Competence. New York and London:

Teachers College, Columbia University.

Sundem, G., Krieger, J. \& Pickiewicz, K. (2008). 10 Languages You'll Need Most in the Classroom, Thousand Oaks: Corwin Press. 